\title{
REDUCING TOBACCO CONSUMPTION
}

\section{Simon Chapman}

School of Public Health

University of Sydney

With the exception of Singapore, ${ }^{1}$ where few women smoke for cultural reasons, and Sweden, where the high use of oral sucking tobacco (or snus) in men has depressed cigarette smoking, ${ }^{2}$ Australia now has the lowest national smoking prevalence in the world. In Australia in 2001, 19.5 per cent of people over 14 years of age smoked on a daily basis. ${ }^{3}$ This is the first time that smoking prevalence in Australia has fallen below 20 per cent. This article describes the decline in smoking prevalence in Australia, discusses how this has been achieved, and outlines strategies for decreasing smoking prevalence in the future.

\section{TOBACCO SMOKING:THE DECLINE IN PREVALENCE AND CONSUMPTION}

In Australia, there has been a largely uninterrupted decline in smoking prevalence since the early 1960 s, when an estimated 58 per cent of men and 28 per cent of women smoked (Figure 1). ${ }^{4}$

\section{FIGURE 1}

\section{CHANGES IN SMOKING PREVALENCE IN MEN AND} WOMEN, AUSTRALIA, 1945-1998

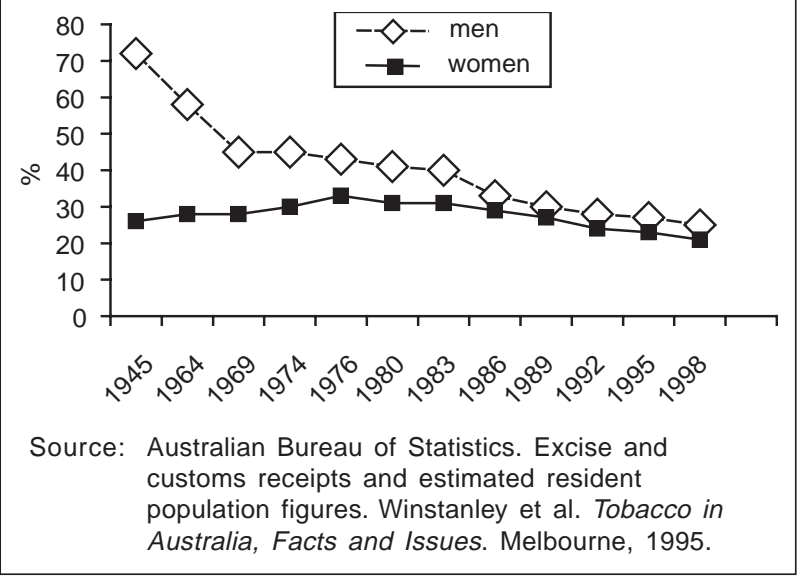

As well as a decline in smoking prevalence, most noticeably in men, smoking frequency-that is, the amount of tobacco consumed by smokers-has also declined dramatically since the 1960s (Figure 2).

As there is a relationship between tobacco smoking and disease, it would be expected that these large-scale declines in prevalence and consumption would be followed by a lagged decline in the mortality and morbidity due to tobacco smoking.

Perhaps the most uncomplicated illustration of this has occurred with lung cancer in men. In NSW, between 1973 and 1998, there has been a 13.4 per cent decline in the incidence of lung cancer $(69.3 / 100,000$ to $60.0 / 100,000$ person years). Between 1973 and 1984, the incidence rate of lung cancer in men rose by an average of 1.3 per cent per year, and since then has decreased by 1.9 per cent per year. ${ }^{5}$ In women, the incidence rate for lung cancer increased by 3.9 per cent per year between 1973 and 1993 but thereafter has remained stable, again reflecting the historical trend in smoking rates for women. Lung cancer remains the leading cause of cancer death in Australia. Death rates from coronary heart disease fell by 59 per cent in men and 55 per cent in women between 1980 and 2000, in large part because of changes in risk factors such as smoking. ${ }^{6}$

\section{How has this been achieved?}

Australia has what are perhaps the world's most advanced comprehensive tobacco control policies and programs. Because of these policies and programs, Australia has:

- the world's most expensive cigarettes, second only to Hong Kong; 7

- among the world's most prominent health warnings on cigarette packets; ${ }^{8}$

- a total ban on all advertising and promotion of cigarettes;

- national campaigns for tobacco control that are emulated internationally; ${ }^{9}$

- Quitline services that provide advice and support to smokers trying to quit smoking;

- extensive advocacy, via news media, for tobacco control; ${ }^{10}$

- legislation that prohibits tobacco smoking in large buildings, public transport, and in restaurants; ${ }^{11}$

- the widespread adoption of smoke-free homes (according to the latest estimate, 71.5 per cent of homes are smoke free); ${ }^{12}$

- litigation by smokers and passive smokers against tobacco companies, which has attracted widespread media attention. ${ }^{13}$

\section{WHERE TO FROM HERE?}

In order to achieve a further reduction in prevalence and consumption of tobacco smoking, Australia needs to continue the comprehensive tobacco control programs already in place, as well as:

- providing more funding for sustainable, high profile public information campaigns for tobacco control;

- closing the loopholes in existing legislation relating to environmental tobacco smoke to ensure that all workplaces (including licensed premises) are smoke free;

- tougher health warnings on cigarette packets; 


\section{FIGURE 2}

\section{CHANGES IN ADULT PER CAPITA TOBACCO CONSUMPTION, AUSTRALIA, 1970-2000}

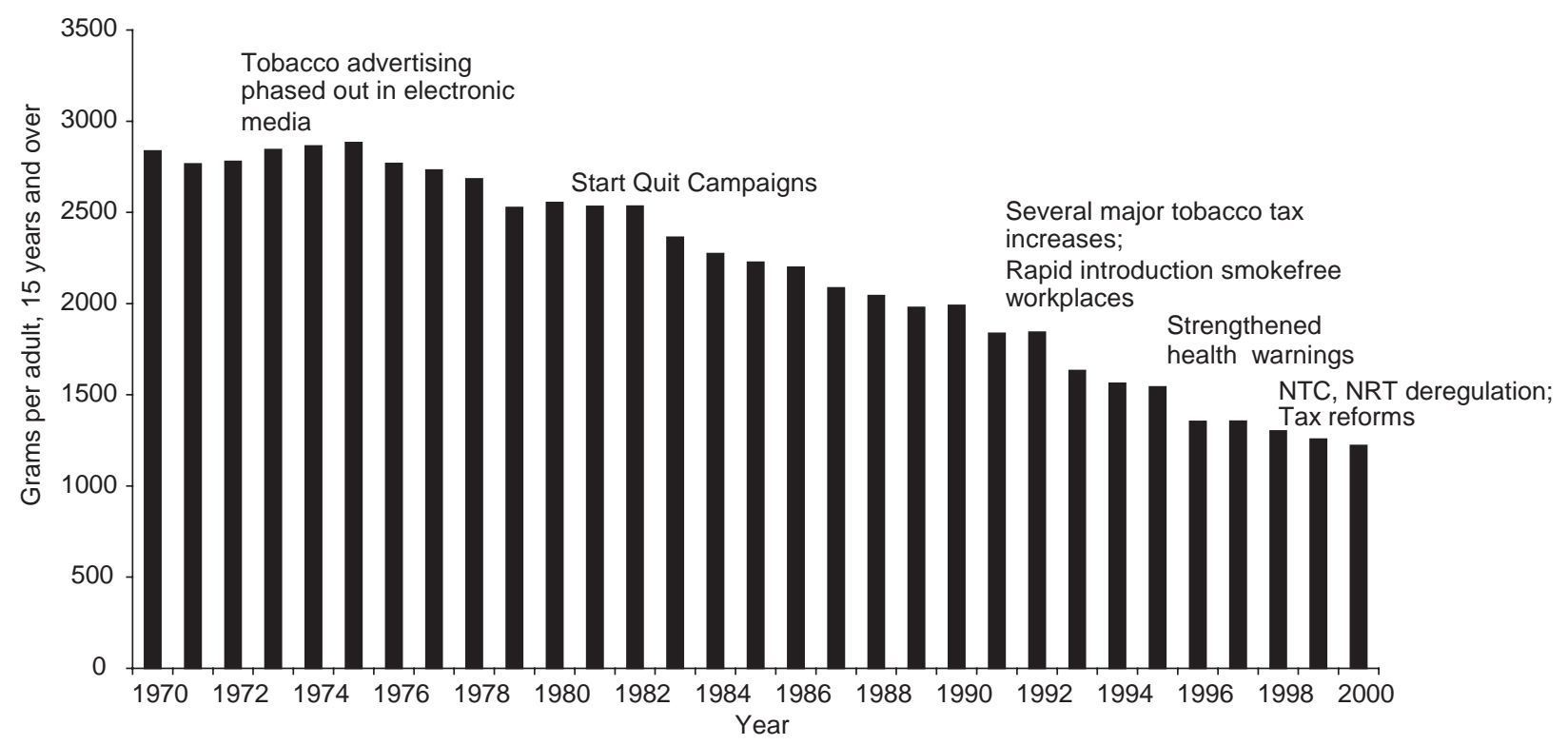

NTC = National Tobacco Campaign NRT = Nicotine Replacement Therapy

Source: Australian Bureau of Statistics. Excise and customs receipts and estimated resident population figures. Winstanley et al. Tobacco in Australia, Facts and Issues. Melbourne, 1995.

- regulating tobacco products to ban additives and flavourings that make smoking more palatable to smokers and to children;

- developing and implementing a regulatory framework to control all aspects of tobacco production, packaging, marketing, and taxation.

The NSW Tobacco Action Plan 2001-2004 sets out the NSW Government's commitment to the prevention and reduction of tobacco-related harm in New South Wales.

For further information about the NSW Tobacco Action Plan 2001-2004, contact the Tobacco and Health Branch on telephone (02) 93919111 . The Plan can be downloaded from the NSW

Department of Health website at www.health.nsw.gov.au.

Printed copies can be obtained by contacting the Better Health Centre on (02) 98790443.

For further information and support with quitting smoking, call the Quitline on 131848 for the cost of a local call from anywhere in NSW. Quitline is a free 24 hour service.

\section{REFERENCES}

1. World Health Organization and American Cancer Society. Tobacco Control Country Profiles at www5.who.int/tobacco/ repository/tld104/Singapore.pdf.

2. Henningfield JE, Fagerstrom KO. Swedish Match Company, Swedish snus and public health: A harm reduction experiment in progress? Tobacco Control 2001;10:253-7.

3. Australian Institute of Health and Welfare. 2001 National Drug Strategy Household Survey-State and Territory Supplement. Drug Statistics Series No. 10. Canberra: AIHW, 2001. Online at www.aihw.gov.au/publications/phe/ ndshs01sts/index.html.

4. Woodward SD. Trends in cigarette consumption in Australia. Aust N Z J Med 1984;14:405-7.

5. Goumas C, O'Connell D, Smith D, Armstrong B. Lung cancer in NSW 1973-1998. Sydney: The Cancer Council NSW, 2001.

6. Australian Institute of Health and Welfare. Epidemic of coronary heart disease and its treatment in Australia. Canberra: AIHW, 2002. Online at www.aihw.gov.au/ publications/cvd/echdta/index.html.

7. Lal A, Scollo M. Big Mac index of cigarette affordability. Tobacco Control 2002;11:280-2.

8. Borland R, Hill D. The path to Australia's tobacco health warnings. Addiction 1997;92:1151-7.

9. Australia's National Tobacco Campaign. Evaluation Report 2: Every cigarette is doing you damage. Canberra: Commonwealth of Australia, 2000. Online at 
www.health.gov.au/pubhlth/publicat/document/ tobccamp_2.pdf.

10. Chapman S, Wakefield M. Tobacco control advocacy in Australia: Reflections on 30 years of progress. Health Education \& Behaviour 2001;29:274-89.

11. Chapman S, Borland R, Lal A. Has the ban on smoking in NSW restaurants worked? A comparison of restaurants in Sydney and Melbourne. Med J Aust 2001;174:512-5.
12. NSW Department of Health. NSW Health Survey 1997 and 1998 (HOIST). Sydney: NSW Department of Health, 2000. Available online at www.health.nsw.gov.au.

13. Wakefield M, Clegg-Smith K, Chapman S. Framing of news coverage about the Marlene Sharp legal judgement: A tipping point for smoke-free public places in Australia? Melbourne: VicHealth Centre for Tobacco Control., 2003.

\section{THE DECLINE IN GUN DEATHS}

\section{Simon Chapman}

School of Public Health

University of Sydney

On 10 June 1996, following the Port Arthur massacre on 26 April of that year, an historic agreement between Australia's state and territory governments introduced a raft of radical reforms to Australia's gun laws. This article describes the decline in gun deaths following those reforms, which had been advocated by public health, domestic violence and law reform groups during the decade previous. ${ }^{1}$

The main provisions of the gun reforms were:

- a ban on the importation, ownership, sale, resale, transfer, possession, manufacture or use of semiautomatic and pump-action shotguns and rifles;
- a compensatory 'buyback' scheme, funded by an increase in the Medicare levy, whereby gun owners would be paid the market value of prohibited guns they handed in. Over 644,000 guns were removed from the community in the buyback;

- the registration of all firearms, as part of an integrated shooter licensing scheme;

- shooter licensing, based on a requirement to prove a 'genuine' reason for owning a firearm;

- requirements that all guns be stored securely;

- nationally uniform gun laws among Australia's states and territories.

One of the main provisions of the 1996 reforms was the banning of semi-automatic and pump action shot guns, which are guns frequently used in mass killings and sieges because of their capacity to fire many rounds of

\section{FIGURE1}

NUMBERS OF FIREARM RELATED DEATHS BY INTENT, AUSTRALIA, 1979 TO 1999

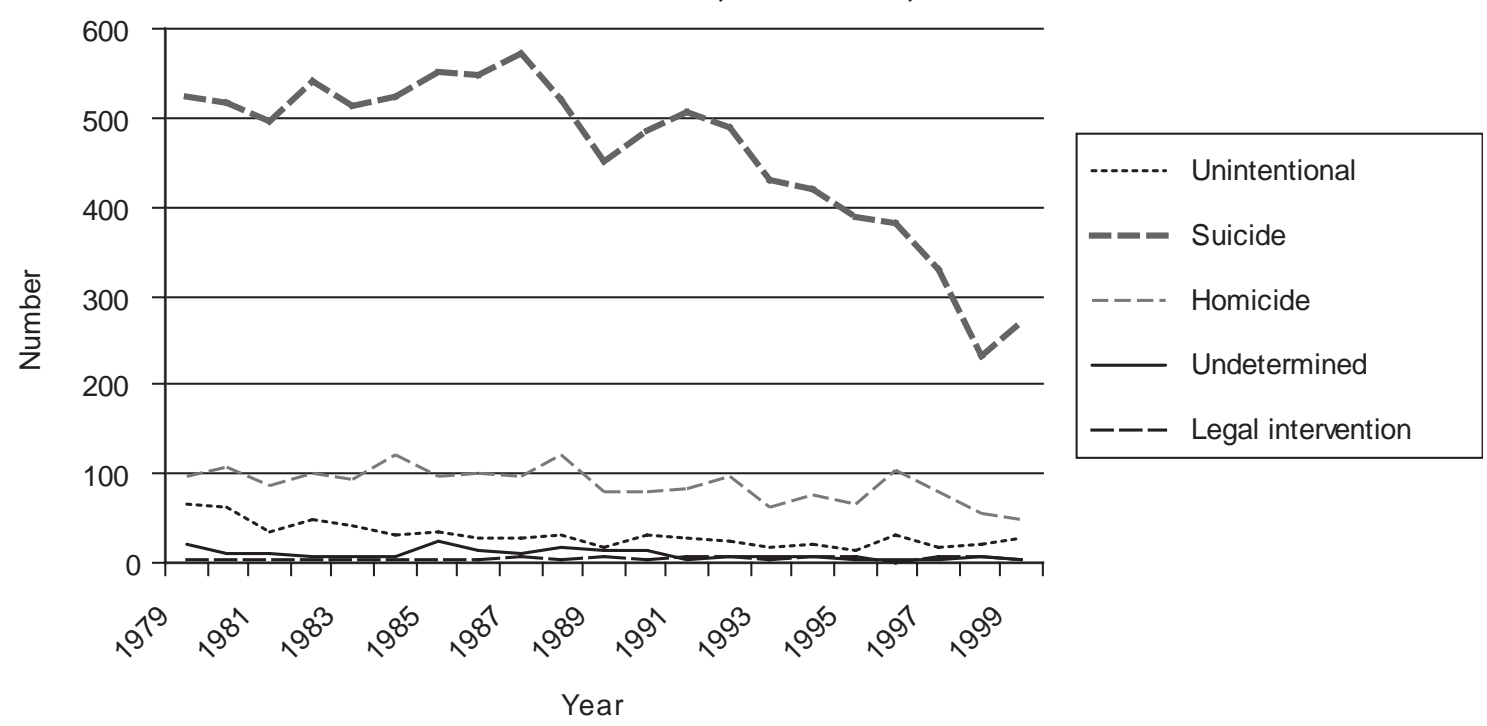

Source: Research Centre for Injury Studies, Flinders University, Adelaide. A data table for this Figure is available on online at www.nisu.flinders.edu.au/data/phonebook/queries/guns.php. 